\section{THE SYNTHESIS AND BIOLOGICAL ACTIVITY OF A NOVEL SERIES OF 2-ARYL PENEMS}

Sir:

The penems are a series of synthetically prepared $\beta$-lactam derivatives which were initially designed ${ }^{1)}$ by combining the structural features of both the 5 -membered thiazoline ring of the penicillins with the enamine-like double bond of the cephalosporins. Further introduction of a $6 S$-(1R-hydroxyethyl) substituent, found in the carbapenem thienamycin, to the corresponding position in the penem nucleus has resulted in highly potent and broad spectrum antibiotics. We now wish to report the investigation of a new series of penems which bear a substituted phenyl group in the 2-position. It has been found that the level of potency of these compounds depends critically on the nature of the substituent on the phenyl ring.

Much attention has been paid to penems with a variety of substituents in the 2-position, particularly 2-alkylthio ${ }^{2)}, 2$-thiomethyl ${ }^{3)}, 2$-oxymethyl ${ }^{4)}$ and 2 -aryloxy ${ }^{5)}$. Conversely, until recently ${ }^{6,7}$, only scant attention has been paid to 2-arylpenems despite the fact that a 2-phenylpenem was one of the first examples prepared ${ }^{1)}$. We sought therefore to investigate such a series of 2-arylpenems and in particular to vary the nature of the substituent on the phenyl ring. Furthermore, our experience in the 2-aryloxypenem series ${ }^{5)}$ suggested that a carbamoylphenyl penem might be a highly potent antibacterial agent and was therefore an especially attractive target.

A short and high-yielding route to the arylpenem nucleus was required. It was reasoned that if the recently discovered oxalimide cyclization ${ }^{8)}$ could be employed for the 2-aryl series then the readily available thiobenzoic acids (from benzoyl chlorides and $\mathrm{H}_{2} \mathrm{~S}$ ) would provide convenient starting materials for such a route. Thus, reaction of the well known tert-butyldimethylsilyl (TBDMS)-protected acetoxyazetidinone $(1)^{9)}$ with the thiobenzoic acids (2), as their sodium salts, gave the intermediate thioesters (3) in good yields. These thioesters all exhibited a large coupling constant between $3-\mathrm{H}$ and 4- $\mathrm{H}(J=2.3 \sim 2.5 \mathrm{~Hz})$ indicating a trans configuration across the ring and confirming that displacement of the acetoxy group occurs with retention of stereochemistry. Acylation of the azetidinone $\mathrm{NH}$ with para-nitrobenzyl (PNB) oxalyl chloride afforded the desired oxalimide intermediates (4), which could be isolated but were not stable to chromatography on silica gel. Direct treatment of the oxalimides (4) with two equivalents of triethyl phosphite in refluxing xylene smoothly afforded the protected penems (5) in good to excellent yields. These were subsequently desilylated with tetrabutylammonium fluoride and the resulting penem PNB-esters (6) hydrogenated to provide the desired penems (7), which were isolated as their potassium salts. While this route worked very well for the unsubstituted phenyl penem (7a) and for a variety of simple substituents $(\mathbf{7 b} \sim \mathbf{7 f})$, and indeed even for the secondary amide penems ( $7 g$ and $7 \mathbf{h}$ ) it failed completely to provide the sought-after primary amide (7i). It appeared that although the primary amide intermediate (3i) could be obtained its acylation with PNB-oxalyl chloride was complex, presumably because of competing acylation at both the azetidinone $\mathrm{NH}$ and the primary amide, and none of the cyclized product (5i) was obtained. In fact, during some attempts at this reaction small amounts of the cyanopenem (5k) were isolated providing an indication that reaction had occurred at the amide group.

A less direct route to the primary amide, which utilized a protected carboxyl strategy, was therefore adopted. The half ester-half thioacid (2m), in which the latent carbamoyl function is protected as a 3,4-dimethoxybenzyl (DMB) ester ${ }^{10)}$, was carried through the sequence and the penem DMB-ester (6m) obtained in good yields. Deprotection of the DMB moiety using 2,3-dichloro-5,6-dicyano-1,4benzoquinone ${ }^{10)}$ provided the penem free carboxylic acid (6n) and conversion of the acid to the primary amide (6i) was accomplished by a simple activated ester strategy. Thus, the free acid (6n) was reacted with 1-hydroxybenzotriazole in acetonitrile, using 1-(3-dimethylaminopropyl)-3-ethylçarbodiimide as a coupling reagent. The resulting active ester was treated with a solution of ammonia in acetonitrile to provide the desired amide (6i) cleanly, and in good yield.

The meta-carbamoylphenyl penem (6q) was obtained by a similar sequence starting with the DMB-ester (2p) and both amide PNB-esters (6i and 6q) were deprotected in the usual manner to give the amide potassium salts ( $\mathbf{7} \mathbf{i}$ and $\mathbf{7 q}$ ), respectively, (7i: ${ }^{1} \mathrm{H}$ NMR $\left(250 \mathrm{MHz}, \mathrm{D}_{2} \mathrm{O}\right) \delta 7.80,7.50(4 \mathrm{H}$, $\mathrm{ABq}, \mathrm{Ar} H), 5.79\left(1 \mathrm{H}, \mathrm{d}, J_{5,6}=1.1 \mathrm{~Hz}, 5-\mathrm{H}\right), 4.26$ $\left(1 \mathrm{H}, \mathrm{m}, \mathrm{CHCH}_{3}\right), 3.99\left(1 \mathrm{H}, \mathrm{dd}, J_{5,6}=1.1 \mathrm{~Hz}\right.$ and $\left.J_{6,8}=5.9 \mathrm{~Hz}, 6-\mathrm{H}\right), \quad 1.30\left(3 \mathrm{H}, \mathrm{d}, J_{8,9}=6.3 \mathrm{~Hz}\right.$, $\left.\left.\mathrm{CHCH}_{3}\right)\right)$ and $\left(7 \mathbf{q}:{ }^{1} \mathrm{H}\right.$ NMR $\left(250 \mathrm{MHz}, \mathrm{D}_{2} \mathrm{O}\right) \delta 7.77$ 


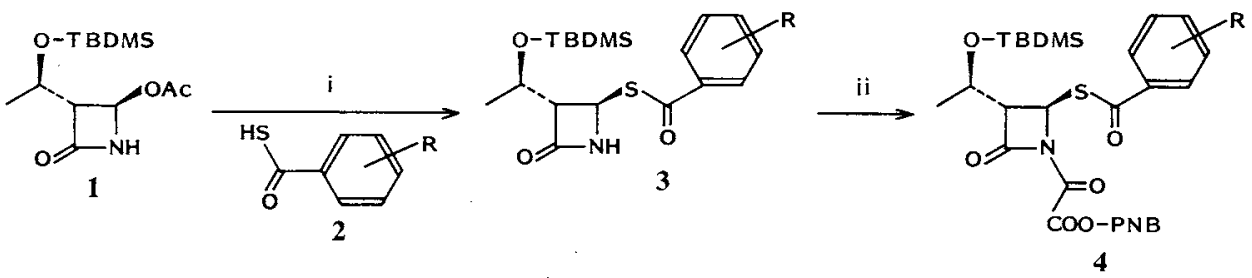

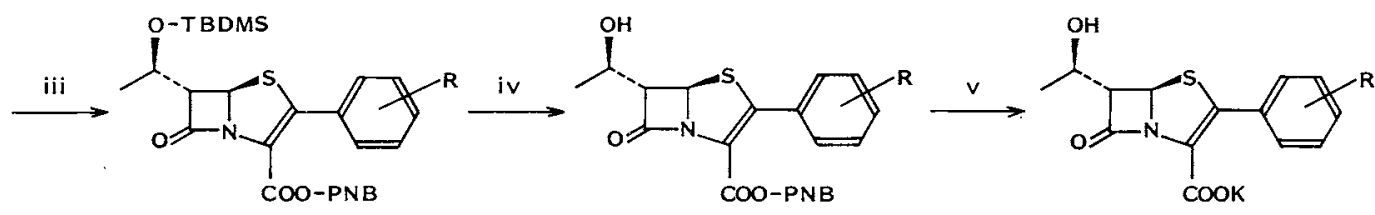

5

6

7

$\begin{array}{llll}\text { a } & \mathrm{R}=\mathrm{H} & \text { h } & \mathrm{R}=4-\mathrm{CONHCH}_{3} \\ \text { b } & \mathrm{R}=4-\mathrm{F} & \text { i } & \mathrm{R}=4-\mathrm{CONH} \\ \text { c } & \mathrm{R}=4-\mathrm{Cl} & \text { k } & \mathrm{R}=4-\mathrm{CN} \\ \text { d } & \mathrm{R}=4-\mathrm{OCH}_{3} & \text { m } & \mathrm{R}=4-\mathrm{COODMB} \\ \text { e } & \mathrm{R}=4-\mathrm{SCH}_{3} & \text { n } & \mathrm{R}=4-\mathrm{COOH} \\ \text { f } & \mathrm{R}=3-\mathrm{SCH}_{3} & \text { p } & \mathrm{R}=3-\mathrm{COODMB} \\ \text { g } & \mathrm{R}=4-\mathrm{CONH}_{2} \mathrm{Pr} & \text { q } & \mathrm{R}=3-\mathrm{CONH}_{2}\end{array}$

Reagents: i) $\mathrm{NaOH}$, acetone; ii) $\mathrm{ClCOCOOPNB},(2-\mathrm{Pr})_{2} \mathrm{NEt}, \mathrm{CaCO}_{3}$, dichloromethane; iii) $\mathrm{P}(\mathrm{OEt})_{3}$, xylene, reflux; iv) $(\mathrm{Bu})_{4} \mathrm{NF}, \mathrm{AcOH}, \mathrm{THF}$; v) $\mathrm{H}_{2}, \mathrm{Pd}-\mathrm{C}, \mathrm{KHCO}_{3}$, dioxane-water.

Table 1. In vitro antibacterial activities ${ }^{a}$ of 2-aryl penems.

\begin{tabular}{|c|c|c|c|c|c|c|}
\hline \multirow{3}{*}{ Organism } & & \multicolumn{5}{|c|}{ Compound } \\
\hline & & $7 \mathbf{a}$ & $7 d$ & $7 e$ & $7 \mathbf{i}$ & $7 q$ \\
\hline & $\mathrm{R}=$ & $\mathrm{H}$ & $4-\mathrm{OCH}_{3}$ & $4-\mathrm{SCH}_{3}$. & 4- $\mathrm{CONH}_{2}$ & $3-\mathrm{CONH}_{2}$ \\
\hline Streptococcus pyogenes A77 & & $<0.05$ & $<0.05$ & $<0.05$ & 0.01 & 0.01 \\
\hline S. pyogenes A 308 & & $<0.05$ & $<0.05$ & $<0.05$ & 0.01 & 0.006 \\
\hline S. faecium MD8b & & 1.56 & 3.12 & 3.12 & 1.56 & 1.56 \\
\hline Staphylococcus aureus SG 511. & & 0.1 & 0.1 & ND & 0.05 & 0.05 \\
\hline S. aureus $285^{\mathrm{b}}$ & & 0.19 & 0.19 & 0.19 & 0.1 & 0.1 \\
\hline S. aureus $503^{\mathrm{b}}$ & & 0.1 & 0.19 & 0.19 & 0.1 & 0.1 \\
\hline Escherichia coli $\mathrm{O} 55$ & & 0.78 & 0.19 & 6.25 & 0.19 & 0.1 \\
\hline E. coli $\mathrm{DCO}$ & & 3.12 & 25 & 50 & 0.78 & 0.39 \\
\hline E. coli $\mathrm{DC} 2$ & & 0.39 & 0.78 & 0.78 & 0.39 & 0.1 \\
\hline E. coli TEM $^{\mathrm{b}}$ & & 1.56 & 12.5 & 25 & 0.39 & 0.19 \\
\hline E. coli $1507 \mathrm{E}$ & & 1.56 & 12.5 & 25 & 0.39 & 0.19 \\
\hline E. coli $\mathrm{KN} 126$ & & 3.12 & 12.5 & 12.5 & 0.39 & 0.1 \\
\hline Klebsiella oxytoca $1082 \mathrm{E}^{\mathrm{b}}$ & & 0.78 & 0.78 & 0.78 & 0.39 & 0.1 \\
\hline$K$. aerogenes $1522 \mathrm{E}$ & & 1.56 & 12.5 & 25 & 0.39 & 0.19 \\
\hline Enterobacter cloacae $\mathrm{P}^{9} 9^{\mathrm{b}}$ & & 12.5 & 100 & 50 & 6.25 & 1.56 \\
\hline E. cloacae $1321 \mathrm{E}$ & & 1.56 & 12.5 & 12.5 & 0.39 & 0.1 \\
\hline Salmonella typhi MZ II & & 0.78 & 6.25 & 12.5 & 0.39 & 0.19 \\
\hline
\end{tabular}

a MICs $(\mu \mathrm{g} / \mathrm{ml})$ were determined by standard 2-fold agar dilution in Mueller-Hinton agar.

$b$ Indicates organism produces a $\beta$-lactamase.

ND: Not determined.

$(2 \mathrm{H}, \mathrm{m}, \operatorname{Ar} H), 7.60(1 \mathrm{H}, \mathrm{dt}, J=1.4$ and $7.9 \mathrm{~Hz}$, $\operatorname{Ar} H), 7.48(1 \mathrm{H}, \mathrm{t}, J=8.0 \mathrm{~Hz}, \operatorname{Ar} H), 5.78(1 \mathrm{H}, \mathrm{d}$, $\left.J_{5,6}=1.5 \mathrm{~Hz}, 5-\mathrm{H}\right), 4.25\left(1 \mathrm{H}, \mathrm{m}, \mathrm{CHCH}_{3}\right), 3.98(1 \mathrm{H}$, $\mathrm{dd}, J_{5,6}=1.5 \mathrm{~Hz}$ and $\left.J_{6,8}=5.9 \mathrm{~Hz}, 6-\mathrm{H}\right), 1.30(3 \mathrm{H}$, d, $\left.J_{8,9}=6.3 \mathrm{~Hz}, \mathrm{CHCH}_{3}\right)$ ).

Having established a short, high-yielding route to 
2-arylpenems and in particular to the carbamoyl derivatives (7i and $\mathbf{7 q}$ ) we now report that these compounds represent a new and very active series of antibacterials (see Table 1) and that the latter carbamoyl compounds are particularly potent. It is interesting to note that, while the results in Table 1 show that activity of this series of compounds appears to correlate with electron withdrawing ability of the substituent on the phenyl ring (e.g. $\mathbf{7} \mathbf{i}>\mathbf{7} \mathbf{a}>\mathbf{7 d}$ ), the meta-substituted amide $(\mathbf{7 q})$ is $2 \sim 4$-fold more active than the corresponding para-amide (7i). Therefore, the critical effect that the nature of the substituent on the phenyl ring has to the antibacterial activity of these compounds cannot be explained solely in simple electronic terms.

\section{Acknowledgements}

We wish to acknowledge the advice and encouragement of Dr. BARRY Ross at the outset of this project. We are grateful to Mr. Steven Clamp and Mr. Michael Turvill for technical assistance.

\section{STEPHEN CONNOLLY ${ }^{\dagger}$ KEVIN W. MOORE ${ }^{\dagger \dagger}$ MichaEL D. COOKE JOHN G. WALMSLEY Peter H. Bentley}

Hoechst Pharmaceutical Research Laboratories, Milton Keynes, MK7 7AJ, UK

(Received May 7, 1991)

\section{References}

1) Woodward, R. B.: Penems and related substances. Philos. Trans. R. Soc. Lond. B 289: 239 250, 1980

2) Oida, S.; A. Yoshida, T. Hayashi, N. Takeda, T.
Nishimura \& E. OHKI: Synthesis of penems and their antibacterial activities. J. Antibiotics 33: $107 \sim 109$, 1980

3) Franceschi, G.; M. Alpegiani, A. Bedeschi, M. Foglo \& E. Perrone: A new class of penems, the 2-heterocyclyl(thio)methyl derivatives. J. Antibiotics 37: $685 \sim 688,1980$

4) Franceschi, G.; M. Foglio, M. Alpegiani, C. Battistini, A. Bedeschi, E. Perrone, F. Zarini, F. Arcamone, C. D. Bruna \& A. Sanfillippo: Synthesis and biological properties of sodium $(5 R, 6 S, 8 R)-6 \alpha$-hydroxyethyl-2-carbamoyloxymethyl-2-penem-3-carboxylate (FCE 22101) and its orally absorbed esters FCE 22553 and FCE 22891. J. Antibiotics 36: $938 \sim 941,1983$

5) CoOke, M. D.; K. W. Moore, B. C. Ross \& S. E. TURNER: Stereoselective synthesis of a $(5 R, 6 S)$-6$[(R)$-1-hydroxyethyl $]$-2-aryloxypenem. J. Chem. Soc. Chem. Commun. 1983: 1005 1006, 1983

6) Bedeschi, A.; G. Visentin, E. Perrone, F. Giudici, F. Zarini, G. Franceschi, G. Meinard, P. Castellani, D. Jabes, R. Rossi \& C. Della Bruna: Synthesis and structure-activity relations in the class of 2-(pyridyl)penems. J. Antibiotics 43: 306 313, 1990

7) Perrone, E.; M. Alpegiani, A. Bedeschi, F. Giudici, F. Zarini, G. Franceschi, C. Della Bruna, D. JABES \& G. MEINARDI: Novel quaternary ammonium penems: The [(pyridinio)methyl]phenyl derivatives. J. Antibiotics 40: 1636 1639, 1987

8) Battistini, C.; C. Scarafile, M. Foglio \& G. FRANCESCHI: A new route to penems and carbapenems. Tetrahedron Lett. 25: 2395 2398, 1984

9) OIDA, S.: 27. Penems, synthetic approach to thienamycin analogues. In Recent Advances in the Chemistry of $\beta$-Lactam Antibiotics. Special Publication No. 38. Ed., G. I. GrEGORY, pp. $330 \sim 348$, The Royal Society of Chemistry, 1981

10) KIM, C. U. \& P. F. Misco: New oxidatively removable carboxy protecting groups. Tetrahedron Lett. 26: $2027 \sim 2030,1985$

\footnotetext{
Present address: † Fisons Pharmaceuticals, Medicinal Chemistry, Bakewell Road, Loughborough, Leics, UK.

${ }_{\dagger}$ Merck, Sharp \& Dohme, Neuroscience Centre, Terlings Park, Harlow, Essex, UK.
} 